\title{
Infections and the parturient: anaesthetic considerations
}

\section{Particjpants}

J.M. Davies, MSC MD FRCPC (Chairman)

Department of Anaesthesia, Foothills Hospital at the University of Calgary. Calgary. Alberta

John M. Thistlewood, MBBS BSC FFARCS FRCPC

Department of Anaesthesia, Foothills Hospital at the University of Calgary, Calgary, Alberta

(The febrile parturient)

Stephen H. Rolbin, MDCM FRCPC

Department of Anaesthesia, Mount Sinai Hospital,

The University of Toronto, Toronto, Ontario

(AIDS and hepatitis: a guide for obstetrical anaesthetists)

M. Joanne Douglas MD FRCPC

Department of Anaesthesiology, The University of British Columbia and The Grace Hospital, Vancouver, British Columbia

(Herpes virus infections of pregnancy)

\section{Introduction}

Practitioners of obstetric anaesthesia most often deal with healthy parturients; serious infections with anaesthetic implications are infrequently encountered. Indeed, in the latest Report on Confidential Enquiries into Matemal Mortality, the five major causes of death in 1979-1981 were hypertensive diseases of pregnancy, pulmonary embolism, anaesthesia, ectopic pregnancy and amniotic fluid embolism. Between 1970-1972 and 1979-1981, matemal deaths from sepsis have decreased from 66 to 15 per million mothers delivered.

Despite declining mortality rates from bacterial infec-

Based on presentations given during the Obstetric Anaesthesia Luncheon at the 1987 Anmual Meeting of the Canadian Anaesthetists' Society in Calgary, Alberta.

Address correspondence to: Dr. J.M. Davies, Department of Anuesthesia, Foothills Hospital, 1403-29th St. N.W., Calgary, Alberta, T2N 2 T9. tions, a number of sepsis-related problems with anaesthetic implications still remain. These include the provision of regional anaesthesia to the febrile parturient and the increasing numbers of women infected with the herpes, HIV (AIDS), and hepatitis viruses. These subjects were the topic of the Obstetric Anaesthesia Luncieon at the 1987 Canadian Anaesthetists' Society Annual Meeting in Calgary. Dr. J.M. Thistlewood, Calgary, considered the question of whether or not the febrile patient should receive regional analgesia/anaesthesia for childbirth. He reviewed the incidence of bacteraemia, epidural vein puncture, and epidural space abscess. Dr. Joanne Douglas, Vancouver, defined the various states of viral infections and then discussed anaesthetic problems posed by those of the herpes group. Finally, Dr. Stephen Rolbin, Toronto, presented a guide for obstetrical anaesthetists when dealing with patients with AIDS or hepatitis.

\section{Reference}

1 Report on Confidential Enquiries into Matemal Deaths in England and Wales 1979-1981. Her Majesty's

Stationery Office, May 1986, London.

\section{The febrile parturient}

The obstetric anaesthesia literature provides little guidance with regard to intrapartum analgesia for the febrile parturient and her fetus. The concern is the risk of epidural abscess formation should bacteraemic blood be released into the epidural space. Infections and other skin abnormalities at the site of epidural placement are an absolute contraindication whilst fever, and therefore possible systemic sepsis, may be a relative or absolute contraindication.

Overall abjectives include:

- reduction of matemal pain-induced stress, 